\title{
BJR \\ - RESEARCH \\ Coating of titanium with hydroxyapatite leads to decreased bone formation
}

\author{
A STUDY IN RABBITS
}

\section{B. G. Bøe, R. Ø. Støen, L. B. Solberg, F. P. Reinholt, J. E. Ellingsen, L. Nordsletten}

From Ringerike Hospital, Hønefoss, Norway

B. G. Bøe, MD, PhD Orthopaedic Surgeon

R. Ø. Støen, MD, Orthopaedic Resident

Vestre Viken HF, Ringerike Hospital, Postboks 3024, 3501 Hønefoss, Norway.

L. B. Solberg, MD, Orthopaedic Resident L. Nordsletten, MD, PhD, Professor, Orthopaedic Surgeon Oslo University Hospital Ullevål, Orthopaedic Department, Postboks 4956 Nydalen, 0424 Oslo, Norway.

I F. P. Reinholt, MD, PhD, Professor, Pathologist OUS HF Rikshospitalet, Pathology Department, Postboks 4950 Nydalen, 0424 Oslo, Norway.

= J. E. Ellingsen, DDS, PhD, Professor, Specialist in Prosthetic Dentistry

Oral Research Laboratory, Institute for Clinical Dentistry, University of Oslo, PO Box 1109 Blindern, NO-0317 Oslo, Norway.

Correspondence should be sent to $\operatorname{Dr}$ B. G. Bøe; e-mail: berte2@mac.com

10.1302/2046-3758.16.2000050 $\$ 2.00$

Bone Joint Res 2012;1:125-30. Received 29 December 2011; Accepted after revision 30 May 2012

\section{Objectives}

An experimental rabbit model was used to test the null hypothesis, that there is no difference in new bone formation around uncoated titanium discs compared with coated titanium discs when implanted into the muscles of rabbits.

\section{Methods}

A total of three titanium discs with different surface and coating (1, porous coating; 2 , porous coating + Bonemaster (Biomet); and 3, porous coating + plasma-sprayed hydroxyapatite) were implanted in $\mathbf{1 2}$ female rabbits. Six animals were killed after six weeks and the remaining six were killed after 12 weeks. The implants with surrounding tissues were embedded in methyl methacrylate and grinded sections were stained with MassonGoldners trichrome and examined by light microscopy of coded sections.

\section{Results}

Small amounts of bone were observed scattered along the surface of five of the 12 implants coated with porous titanium, and around one out of 12 porous coated surfaces with Bonemaster. No bone formation could be detected around porous coated implants with plasma-sprayed hydroxyapatite.

\section{Conclusion}

Porous titanium coating is to some degree osteoinductive in muscles.

Keywords: Osteoinduction, Hydroxyapatite, Bonemaster, Implant surface, Porous titanium, Experimental model, Electrochemical method

\section{Article focus}

- Is it possible to avoid osteolysis by improving implant surfaces?

- How can we prove hydroxyapatite to be osteoinductive, not only osteoconductive?

Is Bonemaster (Biomet) osteoinductive in muscle?

\section{Key messages}

- Porous coating is osteoinductive without ceramic coating

- Implants coated with Bonemaster induced formation of bone in muscle

\section{Strengths and limitations}

- When implanting in muscle the researcher can be sure the visible bone is induced

- It is hard to prepare the histological sections thin enough when using metal implants
The amounts of bone were small in each section. There might be better ways to prove the amount of bone

- The number of samples was small

\section{Introduction}

Titanium alloy is frequently used as a material in orthopaedic implants. The degree of surface roughness on the micro and macro levels as well as the chemical composition of the implant coating are of importance for bone-implant integration. ${ }^{1}$ Long-term survival of uncemented total hip replacement is dependent upon early implant fixation securing early stability. ${ }^{2}$ Rough or porous surfaces are considered beneficial for implant fixation, while smooth implant surfaces are more likely to induce fibrous encapsulation that might prevent bone ingrowth. ${ }^{3,4}$ Experimental data show that hydroxyapatite (HA) may enhance bone conduction around titanium implants when HA 
is plasma-sprayed on the implant..$^{5}$ However, plasmaspraying results in a thickness of the coating that implies smoothening and closure of the titanium porous surface (approximately $50 \mu$ to $200 \mu$ ). ${ }^{5}$ Bonemaster (Biomet Deutschland $\mathrm{GmbH}$, Berlin, Germany) is a new electrochemically deposited HA coating, which is only $5 \mu$ thick. A thin coating allows the implant to maintain its rough surface, as the coating follows the surface of the pores without filling the pits. Thus, by combining the known positive effects of $\mathrm{HA}$ and a porous surface, this approach may represent a step forward in optimising the conditions for osseo-integration of an implant. In support, we have previously found favourable bone remodelling in the greater trochanter with a femoral stem coated with Bonemaster in humans. ${ }^{6}$ Porous granules of HA, implanted subcutaneously, have resulted in heterotopic bone formation in dogs. ${ }^{7}$ Yuan et $\mathrm{al}^{8}$ have indicated that differences in bone induction depend upon architecture in the surface of ceramic rods. They implanted two different types of ceramic rods in dorsal muscles of dogs and found induction of bone around rods with pores of $200 \mu$, but no bone around rods with pores of $400 \mu .^{8}$ This study has investigated grit-blasted titanium discs coated with porous coating, Bonemaster or $\mathrm{HA}$ and implanted into muscle in rabbit, in order to disclose possible differences in osteoinductive properties in soft tissues. Our expectation was that discs coated with Bonemaster do not induce bone formation.

\section{Materials and Methods}

Animals. The study was approved by The Norwegian Animal Research Authority (NARA) and conducted in accordance with local regulations. The animals were housed in the Laboratory Animal Unit at The Norwegian School of Veterinary Science and the acclimatisation period before surgery was 24 days.

A total of 12 grey female Chinchilla rabbits, 16 weeks of age and weighing between and $2900 \mathrm{~g}$ and $3400 \mathrm{~g}$, were used in the study. The operations were performed in sterile and standardised conditions. Each rabbit had all three implants placed intramuscularly in the erector spinae muscles, approximately $5 \mathrm{~cm}$ from each other. The implants were secured with a resorbable suture and the skin was closed by intracutaneous suture.

All rabbits were injected $0.8 \mathrm{ml} / \mathrm{kg}$ intramuscularly of a mixture (1:1:1) of Fentanyl $(50 \mu \mathrm{g} / \mathrm{ml}$; Hameln Pharmaceuticals, Hameln, Germany), Dormicum (Midazolam, $5 \mathrm{mg} / \mathrm{ml}$; Panpharma, Fougères, France) and Domitor (Medetomidin, $1 \mathrm{mg} / \mathrm{ml}$; Orion Pharma, Oslo, Norway). After 5 minutes the rabbits were carried from the cage to the operating theatre. A non-steroidal anti-inflammatory drug (Rimadyl $4 \mathrm{mg} / \mathrm{kg}$; Pfizer, Helsinki, Finland) was given immediately subcutaneously. Animals were anaesthetised with Propovet (Propofol, $10 \mathrm{mg} / \mathrm{ml}$; Abbott, Berkshire, United Kingdom) $0.1 \mathrm{ml} / \mathrm{kg}$ intravenously, and in cases of signs of recovery during surgery, anesthesia was maintained with a new dose of Propovet $0.1 \mathrm{ml} / \mathrm{kg}$ intravenously. Lidokel-adrenaline (Lidokain hydrochlorid monohydrate 20 mg, adrenalin tartrate $36 \mu g$; Denamed AS, Oslo, Norway) $1 \mathrm{ml} / 3 \mathrm{~kg}$ was given locally at the site of surgery. Each animal received an injection with $10 \mathrm{ml} / \mathrm{kg}$ of $\mathrm{NaCl}$ infusion (Baxter, Oslo, Norway) subcutaneously (warmed to body temperature) and buprenorphine (Temgesic; RB Pharmaceuticals Ltd, Berkshire, United Kingdom) $0.05 \mathrm{mg} / \mathrm{kg}$ subcutaneously after surgery. The animals were then placed on an isolating plate in their cages with a hot water bottle. Injection with buprenorphine was repeated twice daily for two days. Rimadyl $4 \mathrm{mg} / \mathrm{kg}$ (Pfizer) was administered subcutaneously once daily for two days after surgery. The rabbits were kept in separate cages for two days following surgery. All animals were checked for wound healing and general health condition before they were moved from their single cage to a room with other rabbits. There were no post-operative complications.

At six and 12 weeks post-operatively six rabbits were killed with Zoletil vet. (Virbac; Virbac, Oslo, Norway) and Pentobarbital (pentobarbital natrium 100 mg/ml; Abbott Norge AS, Fornebu, Norway). The implants including a brim of surrounding muscle were immediately dissected free and fixed in $4 \%$ buffered formaldehyde.

Implants. Three different implant surfaces were investigated: 1) porous titanium coating (PC); 2) porous titanium coating and Bonemaster (PC-BM); and 3) porous coating and hydroxyapatite (PC-HA). The implants (Biomet, Swindon, United Kingdom) were discs of forged titanium alloy (Ti-6Al-4V), with a diameter of $10 \mathrm{~mm}$ and a height of $2 \mathrm{~mm}$. By 'porous coating' a layer of small particles is laid onto the metal surface, shaping channels or pores, which increase the surface area. The specifications for the implants in this study were, according to the manufacturer, a mean surface roughness of $41 \mu$ and a maximum roughness depth of $445 \mu$. The plasmasprayed HA coating is approximately $50 \mu$ thick, with a calcium/phosphorous $(\mathrm{Ca} / \mathrm{P})$ ratio of 1.67 and $62 \%$ crystalline (Fig. 1). The electrochemically deposited HA, Bonemaster, was $5 \mu$ thick with a $\mathrm{Ca} / \mathrm{P}$ ratio of 2.0 and $70 \%$ to $72 \%$ crystalline $\mathrm{HA}$, according to the manufacturer.

Histology. The fixed samples were dehydrated in series of increasing alcohol concentrations and embedded in methylmethacrylate (MMA). Each sample was cut in several sections and grinded to a thickness of $10 \mu$ to $20 \mu$ to optimise staining.

The samples were stained with methylene blue, basic fuchsine or Massons-Goldner's trichrome. In the latter, green areas showing homogenous or slightly fibrillar structure with osteocyte-like cells inside and/or osteoblastlike cells at the surface were recorded as bone. The occurrence of bone at the surface of the discs was evaluated from coded sections by three investigators (BGB, LBS, FPR), one of them an experienced clinical pathologist (FPR) with special competence in bone pathology. 


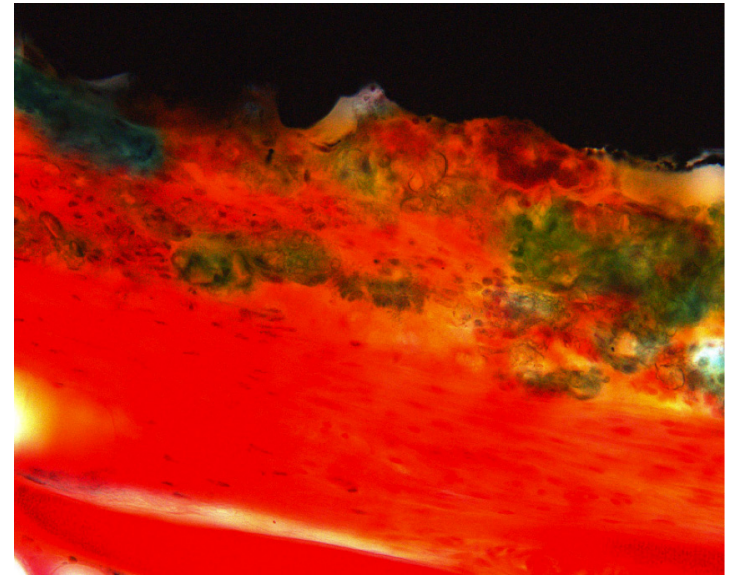

Fig. 1

Light micrograph (primary magnification $\times 40$ ) of implant with porous coating and plasma sprayed hydroxyapatite $(\mathrm{PC}+\mathrm{HA})$ Hydroxyapatite is stained green, however the coating is easy to distinguish from bone by its irregular structure. Titanium is seen as black in the top.

Statistical analysis. Groups were compared for osteoinduction by Fisher's exact test, using STATA software (Statacorp, College Station, Texas). A p-value of $<0.05$ was considered to be significant.

\section{Results}

In sections stained with methylene blue and basic fuchsine it was difficult to distinguish between newly formed bone and other types of connective tissue, but in the sections stained with Masson-Goldners trichrome this distinction was possible.

There was variable amount of fibrous connective tissue around the implants. When present, the amount of bone was generally small with a patchy distribution. Any further quantitation of the amounts of bone was therefore considered less appropriate. Consequently, we decided to present results as presence of 'bone' or 'no bone'. Thus, there were strands of bone running parallel to the implant surface (Fig. 2).

We observed osteoinduction in muscles in five of 12 implants (two after six weeks, three after 12 weeks) coated with porous titanium and in one out of 12 implants (six weeks) coated with Bonemaster and porous titanium (Table I). There was no bone formation around implants with plasma sprayed HA. The HA coating measured to be approximately $50 \mu$ was intact in ten of 12 samples. In two of the samples the coating might have been ripped off during preparation of the sections. In that case, tissue must have been removed too. There was no obvious morphological difference in amount or maturity in bone tissue between six and 12 weeks.

Using Fisher's exact test (linear by linear), there was a statistically significant difference between the distribution of osteoinduction in the three groups for six and

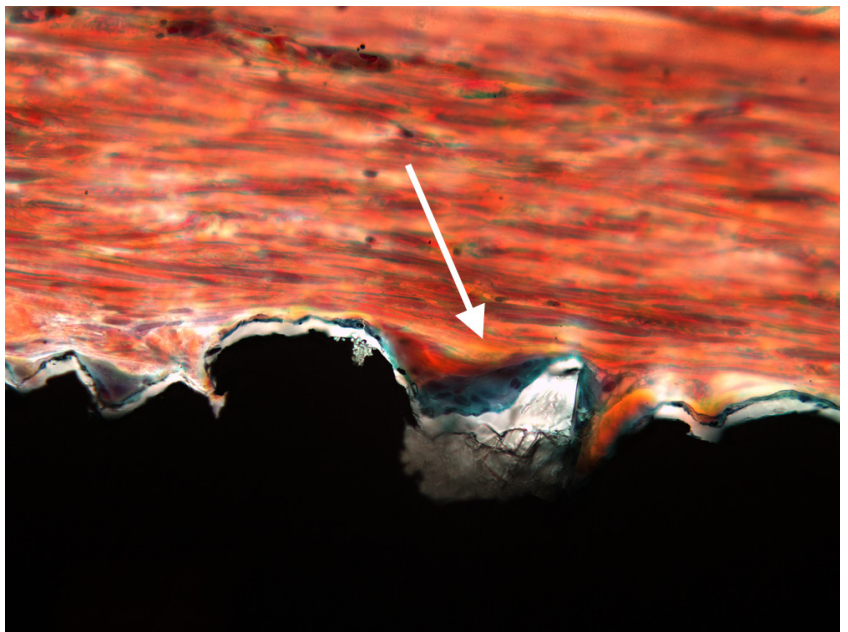

Fig. 2a

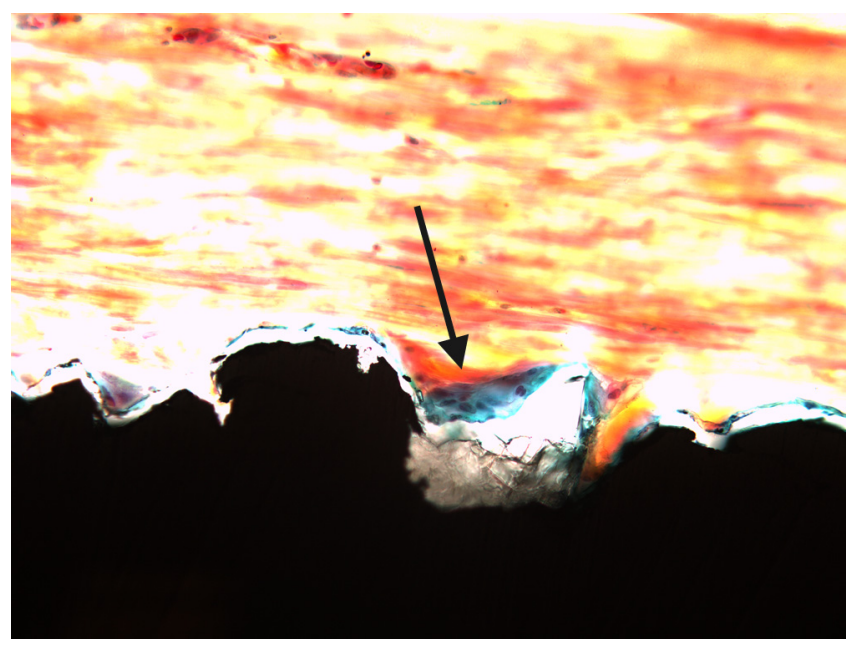

Fig. $2 b$

Two light micrograph images (primary magnification 40, different light filters) of bone formation seen as a thin green line along the implant surface (arrows), which is coated with Bonemaster.

12 weeks combined $(p=0.01)$. The statistics suggest that the distribution among the groups is not likely to be random. Separate analyses for the six and 12-week assessments showed no significant difference between the groups after six weeks $(p=0.27)$, although the difference became significant after 12 weeks $(p=0.049)$.

No signs of infection were observed in any of the specimens. However, in a few sections we observed giant cells in close vicinity to the implant as in a foreign body response.

\section{Discussion}

We observed bone, albeit in small amounts, on porous coated surfaces of titanium. The addition of HA coating on porous titanium appears to reduce the ability to produce bone. However, we found bone tissue around one 
Table I. Results of induction of bone around titanium implants with surfaces of porous coating (PC), porous coating with Bonemaster $(\mathrm{PC}+\mathrm{BM})$ and porous coating with plasma-sprayed hydroxyapatite $(\mathrm{PC}+\mathrm{HA})$ at six weeks, 12 weeks and combined for six and 12 weeks together

\begin{tabular}{lllll}
\hline & PC & PC+BM & PC+HA & p-value \\
\hline Six weeks & $2 / 6$ & $1 / 6$ & $0 / 6$ & 0.27 \\
12 weeks & $3 / 6$ & $0 / 6$ & $0 / 6$ & 0.049 \\
Combined & $5 / 12$ & $1 / 12$ & $0 / 12$ & 0.01 \\
\hline
\end{tabular}

* Fisher's exact test

sample coated with Bonemaster (Biomet). Plasmasprayed HA did not induce bone formation in this experimental model. As far as we know, it has not been shown previously that micro layers of HA can be osteoinductive on a metal surface.

In a recent clinical study of hip prostheses, we compared titanium femoral stems coated with Bonemaster or plasma-sprayed HA. We found less reduction of bone mineral density around the hip prostheses coated with Bonemaster compared with HA during the first two years after surgery. ${ }^{6} \mathrm{HA}$ has proven to be osteoconductive in implant surgery on dogs. ${ }^{5} \mathrm{HA}$ has also been proven to be osteoinductive in soft tissue in dogs, where implanted porous HA granules resulted in heterotopic bone formation after three months. ${ }^{7}$ Barrère et $\mathrm{al}^{9}{ }^{\text {implanted two different types }}$ of metal implants $\left(\mathrm{Ti}_{6} \mathrm{Al}_{4} \mathrm{~V}\right.$ and Hedrocel (Implex Corp., Allendale, New Jersey) coated with octacalcium phosphate (OCP) in the muscles of goats. They observed new bone after 12 and 24 weeks. OCP has a calcium phosphate ratio of 1.33. A porous titanium surface can probably be osteoinductive in itself without ceramics if it is treated chemically and thermally to form an optimal surface structure. ${ }^{10} \mathrm{We}$ found new bone around five of 12 samples with titanium porous coating in our study. The reduced ability to induce bone with ceramic coating might be due to the change in surface structure. The thin Bonemaster coating preserves the irregularity of a porous titanium coating to a greater extent than does plasma-sprayed HA. Kung et al ${ }^{11}$ demonstrated osteoinduction around titanium implants coated with chitosan-collagen subcutaneously in rats. We assume that both physical and chemical properties provided by implants may have an effect on osteogenesis like the structure and composition of the ceramic.

The ability to induce bone formation also depends on animal species. ${ }^{12}$ In the present study a rabbit model was chosen. The observation time was set at six and 12 weeks based on previous studies. ${ }^{13,14}$ Each surface coating was compared within the same animal. This approach reduced the necessary sample size and the influence of individual factors on the bone formation.

Osteoinduction from $\mathrm{HA}$ has been reported previously in dog and pig models. ${ }^{7,15}$ A difference of bone formation between species has also been shown, ${ }^{15}$ in that larger animals seem to produce bone where smaller animals do not. Dogs in particular appear to exhibit properties of bone formation close to humans. ${ }^{15}$ We have not found any reports of subcutaneous osteoinduction in rats or mice after implanting pure titanium or titanium with $\mathrm{HA}$. The lack of osteoinduction might be due to the subcutaneous localisation. Subcutaneous tissue probably has blood supply and bone morphogenic proteins (BMP) levels different from that of muscles. HA and tricalcium phosphate have been shown to be osteoinductive in muscles, but not in subcutaneous connective tissue in the same mice. ${ }^{16}$ Osteoinduction around titanium implants has been demonstrated in subcutaneous tissue in rats, ${ }^{11}$ although the implants in that study were coated with chitosan-collagen. Before we started our study we performed a pilot experiment using rats, which produced negative results regarding bone induction. Based on those results and extended literature search we decided to change animal species. We suggest that differences between species may also be due to differences in expression of proteins affecting cell differentiation, like bone morphogenetic proteins. Approaches including more bone-like coatings by adding the main organic bone component collagen type 1 to $\mathrm{HA}$ have been introduced. ${ }^{13}$ Somewhat surprisingly, the coating with $\mathrm{HA}$ and collagen did not show any benefits when compared with pure HA. In order to achieve successful osseointegration of orthopaedic implants, mature osteoblasts are an essential factor. Gidley et $\mathrm{al}^{17}$ have reported that a combination of lysophosphatic acid (LPA) and Calcitriol (D3) were a particularly potent combination for generating human osteoblast maturation. Mansell et al, $^{18}$ from the same research group, later found that this combination of agents can elicit a very similar response from cells seeded onto either titanium or HA. In this experiment osteoblast maturation was greatest for cells grown upon HA. The HA surface was rougher than titanium, which supports that osteoblast responses are augmented when they are associated with rougher surface features.

The osteoconductivity of HA depends of its crystallinity and stability. ${ }^{19}$ In an in vivo fracture site, unstable mechanical conditions may lead to formation of fibrous tissue, such as that seen in nonunions. ${ }^{20}$ The rate of the earliest stage of bone formation is influenced by the solubility of the HA. ${ }^{21}$ The technique of plasma spraying $\mathrm{HA}$ appears to stimulate more bone than electrochemically deposited HA during the first days after implantation. ${ }^{22}$ Higher bone apposition rate has been shown after seven days and increased bone growth has been shown after four weeks in a dog model. ${ }^{23}$ After this initial period the electrochemically deposited HA has been shown to demonstrate similar tensile strength and higher bone volume in the implant vicinity than plasma sprayed HA. ${ }^{13}$ Yuan et $\mathrm{al}^{24}$ performed a study in which HA cylinders were implanted in dog muscles for 2.5 years. HA was found to induce normal bone with bone marrow in the pores of the HA cylinders. The amount of bone remained stable from 45 days to 2.5 years. The fact that the bone 
did not disappear or expand after the first induction may be clinically relevant. It remains to be seen if higher bone volume initially means anything in relation to osteolysis and the long-term survival of implants. In our experiment the quantity of bone formation was low, and it did not increase between six and 12 weeks. Our results may seem of less clinical relevance but in our opinion the relevance is in the proof of a concept, induction of bone or not.

As indicated above, differences in osteoinduction may be due to local tissue characteristics and thereby the access to osteogenic factors. The area around a fracture or the bone around an implant will be an osteogenic environment in which osteogenic factors will be adsorbed, triggering osteoinduction. The results of Cheng et $\mathrm{al}^{16}$ support this concept. They used haematoxylin and eosin (HE) staining for their first light microscopy examinations (at two, four, six and eight weeks) and then Masson trichrome after 12 weeks. ${ }^{16}$ We found in our study that it was difficult to separate bone tissue from nonmineralised tissue with basic fuchsine and methylene blue, and decided to stain with Masson Goldner's trichrome. Cheng et al $^{16}$ do not describe any problems identifying bone with $\mathrm{HE}$, although Daugaard et $\mathrm{al}^{13}$ used light green in combination with basic fuchsine. In our study, the main reason for needing trichrome staining was due to the limited amount of bone. For later experiments we will consider the use of immunohistochemistry, electron microscopy or PCR in the detection of bone.

The three different surfaces in our study may adsorb proteins and cells differently, leading to differences in the possibility of new bone formation. Furthermore, it may be questionable whether the osteoinduction by BMPs and osteoinduction by inorganic materials are related.

Porous implant surface is believed to lead to enhanced ingrowth of bone. Yamasaki and Sakai ${ }^{7}$ observed that HA granules with micro pores on their surface could induce bone subcutaneously in dogs. No bone was induced in granules without micro pores. Ronold, Lyngstadaas and Ellingsen ${ }^{25}$ studied the effect of surface roughness on tensile strength. They investigated the bone-to-implant retention for titanium implants with different surface roughness created by $\mathrm{TiO}_{-2}$ grit blasting. There was a positive correlation between increasing surface roughness and functional attachment leveled out at surfaces blasted with grains between $180 \mu$ and $220 \mu$. A further increase in roughness did not give an additional improvement in implant retention. Somewhat surprisingly, enhanced amount of bone ingrowth to implant histologic did not lead to increased tensile strength with pull-out testing. There was no significant correlation between the degree of surface roughness, and the bone-to-metal contact. The fine particles in their study were $7.5 \mu$ to $12.5 \mu$, approximately the same size as the thickness of Bonemaster coating (approximately $5 \mu$ ). In the same study the implants blasted with $180 \mu$ to $220 \mu$ particles, resulted in markedly increased strength. ${ }^{25}$
We observed a limited number of giant cells in the proximity of our implants and signs of an inflammatory response have been reported around HA implants before. ${ }^{7}$ Moreover, Fellah et al, $^{26}$ investigating cell response to bicalciumphosphat in rat muscles, found more giant cells around larger implanted particles $(80 \mu$ to $200 \mu$ ) compared with smaller ones $(<20 \mu)$. However, there were more mononucleated macrophages around the smaller particles. ${ }^{26}$

Resorption of HA coating when implanted in bone is seen to various degrees depending on type of metal surface and composition of HA. On porous surfaces the HA coating tends to be resorbed to a larger extent than on grit blasted surfaces. However, in circumstances where HA coating is resorbed, it might be replaced by bone. ${ }^{3}$

In conclusion, we found porous titanium osteoinductive in muscle. Coating with Bonemaster reduced the ability to induce bone. No osteoinduction was observed around HA coated implants.

\section{References}

1. Ellingsen JE, Johansson CB, Wennerberg A, Holmén A. Improved retention and bone-tolmplant contact with fluoride-modified titanium implants. Int J Oral Maxillofac Implants 2004;19:659-666.

2. Engh CA, Bobyn JD, Glassman AH. Porous-coated hip replacement: the factors governing bone ingrowth, stress shielding, and clinical results. J Bone Joint Surg [Br] 1987;69-B:45-55.

3. Overgaard S, Lind M, Rahbek O, Bünger C, Søballe K. Improved fixation of porous-coated versus grit-blasted surface texture of hydroxyapatite-coated implants in dogs. Acta Orthop Scand 1997;68:337-343.

4. Friedman RJ, An YH, Ming J, Draughn RA, Bauer TW. Influence of biomaterial surface texture on bone ingrowth in the rabbit femur. J Orthop Res 1996;14:455-464.

5. Søballe K. Hydroxyapatite ceramic coating for bone implant fixation: mechanical and histological studies in dogs. Acta Orthop Scand Supp/ 1993;255:1-58.

6. Bøe BG, Röhrl SM, Heier T, Snorrason F, Nordsletten L. A prospective randomized study comparing electrochemically deposited hydroxyapatite and plasmasprayed hydroxyapatite on titanium stems. Acta Orthop 2011;82:13-19.

7. Yamasaki H, Sakai H. Osteogenic response to porous hydroxyapatite ceramics under the skin of dogs. Biomaterials 1992;13:308-312.

8. Yuan H, Kurashina K, de Bruijn JD, et al. A preliminary study on osteoinduction of two kinds of calcium phosphate ceramics. Biomaterials 1999;20:1799-1806.

9. Barrère F, van der Valk CM, Dalmeijer RA, et al. Osteogenecity of octacalcium phosphate coatings applied on porous metal implants. J Biomed Mater Res A 2003;66:779-788

10. Fujibayashi S, Neo M, Kim HM, Kokubo T, Nakamura T. Osteoinduction of porous bioactive titanium metal. Biomaterials 2004;25:443-450.

11. Kung S, Devlin H, Fu E, et al. The osteoinductive effect of chitosan-collagen composites around pure titanium implant surfaces in rats. J Periodontal Res 2011;46:126133

12. Aerssens J, Boonen S, Lowet G, Dequeker J. Interspecies differences in bone composition, density, and quality: potential implications for in vivo bone research. Endocrinology 1998;139:663-670.

13. Daugaard H, Elmengaard B, Bechtold JE, Jensen T, Soballe K. The effect on bone growth enhancement of implant coatings with hydroxyapatite and collagen deposited electrochemically and by plasma spray. I Biomed Mater Res A 2009;92:913-921.

14. Soballe K, Hansen ES, Brockstedt-Rasmussen H, Pedersen CM, Bunger C. Bone graft incorporation around titanium-alloy- and hydroxyapatite-coated implants in dogs. Clin Orthop Relat Res 1992;274:282-293.

15. Yang Z, Yuan $\mathbf{H}$, Tong $\mathbf{W}$, et al. Osteogenesis in extraskeletally implanted porous calcium phosphate ceramics: variability among different kinds of animals. Biomaterials 1996;17:2131-2137.

16. Cheng L, Ye F, Yang R, et al. Osteoinduction of hydroxyapatite/beta-tricalcium phosphate bioceramics in mice with a fractured fibula. Acta Biomater 2010;6:15691574. 
17. Gidley J, Openshaw S, Pring ET, Sale S, Mansell JP. Lysophosphatidic acid cooperates with 1alpha,25(OH)2D3 in stimulating human MG63 osteoblast maturation. Prostaglandins Other Lipid Mediat 2006;80:46-61.

18. Mansell JP, Barbour M, Moore C, et al. The synergistic effects of lysophosphatidic acid receptor agonists and calcitriol on MG63 osteoblast maturation at titanium and hydroxyapatite surfaces. Biomaterials 2010;31:199-206.

19. Dhert WJ. Retrieval studies on calcium phosphate-coated implants. Med Prog Technol 1994;20:143-154.

20. El-Hoss J, Sullivan K, Cheng T, et al. A murine model of neurofibromatosis type 1 tibial pseudarthrosis featuring proliferative fibrous tissue and osteoclast-like cells. J Bone Miner Res 2011:Epub.

21. Porter AE, Hobbs LW, Rosen VB, Spector M. The ultrastructure of the plasmasprayed hydroxyapatite-bone interface predisposing to bone bonding. Biomaterials 2002;23:725-733

22. Wang H, Eliaz N, Xiang Z, et al. Early bone apposition in vivo on plasma-sprayed and electrochemically deposited hydroxyapatite coatings on titanium alloy. Biomaterials 2006;27:4192-4203.

23. Daugaard H, Elmengaard B, Bechtold JE, Soballe K. Bone growth enhancement in vivo on press-fit titanium alloy implants with acid etched microtexture. J Biomed Mater Res A 2008;87:434-440.

24. Yuan H, Yang Z, De Bruij JD, De Groot K, Zhang X. Material-dependent bone induction by calcium phosphate ceramics: a 2.5-year study in dog. Biomaterials 2001:22:2617-2623
25. Ronold HJ, Lyngstadaas SP, Ellingsen JE. A study on the effect of dual blasting with TiO2 on titanium implant surfaces on functional attachment in bone. J Biomed Mater Res A 2003:67:524-530.

26. Fellah BH, Josselin N, Chappard D, Weiss $\mathbf{P}$, Layrolle $\mathbf{P}$. Inflammatory reaction in rats muscle after implantation of biphasic calcium phosphate micro particles. $J$ Mater Sci Mater Med 2007;18:287-294.

\section{Funding statement:}

- This work was supported by Smith \& Nephew research grant and the implants were produced and paid for by Biomet Europe.

Author contributions:

- B. G. Bøe: Study design, Operative procedures, Statistical analysis, Writing the paper

- R. Ø. Støen: Operative procedures, Reviewing the paper

- L. B. Solberg: Animal pilot study, Histological examinations, Reviewing the paper

- L. Nordsletten: Study design, Histological examinations, Reviewing the paper

- F. P. Reinholt: Implant preparation, Histological examinations, Reviewing the paper

- J. E. Ellingsen: Implant preparation, Histological examinations

ICMJE Conflict of Interest:

- None declared

C2012 British Editorial Society of Bone and Joint Surgery. This is an open-access article distributed under the terms of the Creative Commons Attributions licence, which permits unrestricted use, distribution, and reproduction in any medium, but not for commercial gain, provided the original author and source are credited. 